\title{
Ante los retos a la cristología de parte de la actual cultura plural
}

\author{
Gabino Uríbarri \\ FACULTAD DE TEOLOGía \\ Universidad Pontificia Comillas (Madrid) \\ guribarri@comillas.edu
}

La presente conferencia fue presentada como ponencia en el XXV Encuentro de Obispos y Teólogos realizado en Madrid entre el 30 y el 31 enero del 2017, que versó sobre "Religión y sociedad multicultural".

\section{INTRODUCCIÓN}

Centrándome en la cristología y en la propuesta que la Iglesia hace desde la comprensión de su fe en Jesucristo, estimo que se dan cuatro áreas mayores en que la comprensión católica choca con elementos fuertes y arraigados en la mentalidad reinante en nuestra actual cultura y sociedad. Resumidamente, tienen que ver con:

1) La investigación histórica sobre Jesús y sus resultados. Pues se parte del crédito que se otorga a lo científico frente al descrédito de las instituciones religiosas.

2) El pluralismo religioso y el relativismo. De ahí que la consideración de Jesucristo como "a un tiempo mediador y plenitud de toda la revelación” (DV 2) y la salvación parezca espontáneamente como una suerte de herejía cultural insostenible: un fundamentalismo intolerante.

3) En nuestro contexto cultural, se sitúa a Jesucristo como uno más al servicio de mi búsqueda y mi viaje espiritual, midiendo su verdad y bondad por su capacidad de generar satisfacción espiritual y emocio-

1 El texto de la ponencia, que estaba preparado para ser leído, ha sido adaptado para su publicación escrita. Agradezco los comentarios que, en su momento, me hicieron los profesores Serafín Béjar (Granada) y Carlos García Llata (Vitoria) a la presentación oral. He incorporado sus pertinentes sugerencias y observaciones. 
nal en medio de un mercado religioso tremendamente competitivo y sin reglas.

4) Por todo ello, sin percibir nítidamente en qué medida sea un salvador eficaz y superior a todas las ofertas de salvación, religiosas o no, difícilmente se dará una adhesión consistente a su persona.

Seguidamente exploro sucintamente cada uno de estos aspectos, de gran envergadura cada uno de ellos. Presentaré, primero, su problemática en un análisis teológico, que intenta discernir los núcleos de la fe cristológica eclesial que en el ambiente de nuestra cultura plural actual quedan más cuestionados. En un segundo paso, trataré de explorar en qué medida la sensibilidad cultural apunta también hacia una cierta apertura para la transmisión de la fe cristiana, a pesar de las dificultades mencionadas. Incluiré también, en este segundo punto, algún tipo de propuesta u orientación pastoral, tratando de iluminar líneas para una acción evangelizadora. Evidentemente, en ningún caso me siento poseedor del monopolio de la verdad. Se trata de un ensayo, en forma de sugerencias e invitación a una mayor profundización, tanto en su vertiente más teórica como en su aplicación pastoral.

\section{JESUCRISTO: ¿SOLAMENTE UN PERSONAJE HISTORICO?}

a) Ciencia histórica versus institución eclesial

1. Más allá de la problemática estrictamente teológica y de método, en la que en seguida entraré, en esta área de fricción se dan la mano el aprecio prácticamente incuestionado de la ciencia, como saber serio, riguroso y objetivo, junto con el desprestigio de las instituciones, específicamente de las religiosas, Iglesia católica incluida ${ }^{2}$. Lo religioso institucional no se encuentra en auge en nuestra cultura. Por lo tanto, la conciencia media se inclina espontánea y pre-reflexivamente por lo que pueda decir la ciencia, en este caso la ciencia histórica, frente a la institución, en este caso la Iglesia, el dogma o la confesión de fe eclesial. De hecho, cada vez que, en este campo, saltan a los medios los cuestionamientos que la institución oficial esgrime ante las opiniones de algún

2 Cf., entre muchos: Z. Bauman, Modernidad líquida (FCE, Buenos Aires ${ }^{14} 2013$; original 2000); Ch. TaYlor, A Secular Age (Harvard U.P., Cambridge [Mass.] 2007; traducción en 2 tomos en Gedisa, Barcelona 2015); G. DAviE, Religion in Britain since 1945: Believing without belonging, Blackwell, Oxford 1994. 
teólogo particular, la opinión pública se alinea masivamente de parte del teólogo particular, aun sin entender nada del fondo de la disputa ni en cuanto al contenido ni en cuanto al método.

2. La investigación histórica sobre Jesús nace emparentada con el proyecto de la teología liberal, que pretendía liberar a Jesús del dogma eclesial$^{3}$. Esto significa que, desde su comienzo, parte de un prejuicio en contra del dogma eclesial y de la transmisión eclesial de la fe. Entre fiarse de la Iglesia o de la ciencia no solamente ha de prevalecer la ciencia, histórica en este caso, sino que además la ciencia histórica ejerce un papel desenmascarador de los engaños aviesos y nocivos promovidos por la institución eclesial. Por eso, la investigación histórica sobre Jesús no solamente prescinde metodológicamente de la fe, sino que en su tenor e impostación original se dirige frontalmente contra la tergiversación eclesial de la frescura original de Jesús, secuestrado espuriamente por intereses ajenos al mismo Jesús. Se propone, por lo tanto, como programa teológico la recuperación del verdadero Jesús, del Jesús auténtico y real: repristinar la imagen de Jesús, largos siglos secuestrada por el dogma, la metafísica griega y la institución eclesial.

Esta impostación se deja sentir en muchos estudios. Entre ellos, marcando la pauta, destaca la famosísima publicación pionera de H. S. Reimarus, debida a su amigo G. E. Lessing. Este fue publicando siete fragmentos (1774-8), con el título genérico de Fragmentos de un anónimo de Wolfenbüttel. El último de ellos se titula algo así como: "Sobre el propósito de Jesús y sus discípulos" 4 , donde se establece un hiato radical entre Jesús y la primitiva comunidad cristiana en la transmisión original y primera de la fe.

3 Entre las múltiples presentaciones, puede verse: A. Vargas-MachUCA, El Jesús histórico. Un recorrido por la investigación moderna (U.P. Comillas, Madrid 2004); Pontificia Comisión Bíblica, "Biblia y Cristología" (trad. R. Sanz Valdivieso, OFM, prólogo O. GONZÁlez de CARDEDAL), en Carthaginensia 4 (1988) 113-168; o en edición bilingüe, latín-español, en C. Granados - L. SÁnchez Navarro (eds.), Enquiridion bíblico (BAC, Madrid 2010) 922-1025; J.J. BARTOLOMÉ, "La búsqueda del Jesús histórico. Una crónica”, en Estudios biblicos 59 (2001) 179-241; A. PUIG I TÀrREG, "La recherche du Jésus historique", en Biblica 81 (2000) 170-201.

4 El título original reza: „Von dem Zwecke Jesu und seiner Jünger“. Hay una traducción italiana: H.S. ReImarus, I frammenti dell'Anonimo di Wolfenbüttel pubblicati da G.E. Lessing, a cura di F. PARENTE (Bibliopolis, Napoli 1977) 349-534. 
3. En consecuencia, a la misma investigación histórica le pertenece el hiato entre el así llamado Jesús histórico y el Cristo de la fe, inicialmente formulada por M. Kähler ${ }^{5}$. Por eso, la cuestión metodológica en este caso se encuentra totalmente revestida de una cuestión teológica del máximo alcance. Si la exégesis bíblica, en este caso la exégesis de cuño histórico, se entiende a sí misma completamente al margen de la fe o si, por el contrario, constituye un momento metodológico imprescindible dentro de la fe y de la metodología teológica ${ }^{6}$. A este respecto, me parece que, cuando J. Ratzinger - Benedicto XVI critica y corrige tanto sus supuestos metodológicos de partida como los contenidos cristológicos a los que dichos supuestos conducen, simplemente extrae consecuencias ineluctables de los planteamientos historicistas de la investigación histórica sobre Jesús?.

5 Der sogennante historische Jesus und der geschichtliche, biblische Christus, 1892. (Reedición Kaiser, München 1953).

6 La confrontación más nítida de las posturas, a mi parecer, se encuentra en „Ein Briefwechsel zwischen Karl Barth und Adolf von Harnack“ (1923), recogida en J. Moltmann (ed.), Anfänge der dialektischen Theologie Teil I. (Chr. Kaiser, München ${ }^{2} 1966$ ), 323-247 (en la primera edición no figura); y en E. Peterson, „Briefwechsel mit Adolf Harnack und ein Epilog" (1928), en E. Peterson, Theologische Traktate (Ausgewählte Schriften 1; Echter, Würzburg 1994) 175-194 (trad. E. PeTERson, Tratados teológicos, Cristiandad, Madrid 1966, 143-158). Véase también A. DEL Agua, "A modo de presentación: Cuestión metodológica y Cristología bíblica hoy", en A. Del Agua (ed.), Transmitir hoy la fe en Cristo, 7-47.

7 Cf. esp. J. RatZINGER, „Schriftauslegung im Widerstreit. Zur Frage nach Grundlagen und Weg der Exegese heute", en J. Ratzinger (ed.), Schriftauslegung im Widerstreit (Quaestiones disputatae 117; Herder, Freiburg 1989) 15-44; traducción española: "La interpretación bíblica en conflicto. Sobre el problema de los fundamentos y la orientación de la exégesis hoy", en L. Sánchez Navarro - C. Granados (eds.), Escritura e interpretación. Los fundamentos de la interpretación biblica (Palabra, Madrid 2003) 19-54; y su prólogo en el primer tomo de Jesús de Nazaret, ahora en Obras completas VI/1. Jesús de Nazaret. Escritos de Cristología (BAC, Madrid 2015) 95-105.

Para más detalles y bibliografía remito a G. URíBARRI, "Para una interpretación teológica de la Escritura. La contribución de J. Ratzinger - Benedicto XVI”, en S. Madrigal (ed.), El pensamiento de J. Ratzinger. Teólogo y Papa (U.P. Comillas - San Pablo, Madrid 2009) 25-65; G. Uríbarri, "La exégesis «teológica» según el Sínodo", en Razón y Fe 259 (marzo 2009) 193-206; L. Schwienhorst-SchÖnberger, „»Keine reine akademische Angelegenheit«. Zum Verhältnis von Erklären und Verstehen in den Jesus-Büchern von Joseph Ratzinger / Benedikt XVI“, en J.-H. TüCK (ed.), Der Theologenpapst. Eine kritische Würdigung Benedikts XVI. (Herder, Freiburg 2013) 184-206. 
4. Con estos presupuestos se entiende, entonces, tanto el resultado fundamental de la aplicación sistemática de la investigación histórica como la tarea principal de la cristología, al menos en las primeras décadas posteriores al concilio Vaticano II.

En cuanto al resultado, lo podemos formular con una triple constatación: (a) El Jesús que surge de la investigación histórica, que prescinde de la fe, es un personaje histórico: mera y exclusivamente un personaje histórico. Siendo un hombre, por muy grande que hubiera sido, no se puede verdaderamente sostener que Él sea el redentor del mundo, el salvador universal, el mediador absoluto y definitivo entre Dios y los hombres, Dios hecho hombre (encarnación). A la postre, la misma confianza en Él, como una fe religiosa verdadera, tampoco se sostiene sólidamente. Desde el punto de vista teológico, la aplicación sistemática de la investigación histórica no solamente no alcanza a proponer la fe eclesial, incluso desde el punto de vista de la construcción de la cristología con una metodología ascendente ${ }^{8}$, sino que conduce a una suerte de (b) neo-nestorianismo9 (división insalvable entre el Jesús histórico y el Cristo de la fe) o (c) de neo-arrianismo ${ }^{10}$ (Jesús no pertenecería de modo irrestricto al rango divino).

5. La gran tarea de la cristología posterior al Vaticano II consistió, básicamente, en mostrar la congruencia y consistencia de la fe eclesial en Jesucristo, del dogma cristológico, en diálogo con la nueva exégesis histórico crítica, a la que el mismo concilio concedió carta de ciudadanía (cf. DV 12). Esta tarea aún no ha concluido. El dogma eclesial, decantado a lo largo de la historia y condensado en los grandes concilios cristológicos de la antigüedad, se formuló de la mano de la teología y la exégesis de la época, la de los Padres. La teología de los Padres no se puede deslindar de su modo de leer la Escritura. Ahora bien, la exégesis

8 Cf. últimamente W. KASPER, „Einführung - Bausteine für eine künftige Christologie", en W. Kasper, Jesus Christus - das Heil der Welt (Walter Kasper Gesammelte Schriften 9; Herder, Freiburg 2016) 15-22, 16-17. Muy lúcido: C.E. Gunton, Yesterday \& Today. A Study in Continuities in Christology (Eerdmans, Grand Rapids [Mi] 1983). Más detalles en G. URíBARRI, La singular humanidad de Jesucristo (San Pablo - U.P. Comillas, Madrid 2008) 45-201.

9 Cf. J. Ratzinger, Un canto nuevo para el Señor (Sígueme, Salamanca 22005) 19, véase: 11-19 y 34. M. Schneider, Teología como biografía. Una fundamentación dogmática (Desclée, Bilbao 2000) 37-8; V. Gómez-Oliver - J.M. Benítez, 31 jesuitas se confiesan (Península, Barcelona 2003) 264-5 (opinión de R. TAFT); G. URÍBARRI, La singular humanidad, passim.

10 Así Ch. Schönborn, Dios ha enviado a su Hijo. Cristología (Edicep, Valencia 2006) 38. 
crítica y científica considera que el método exegético empleado por los Padres no solamente no era científico, y que hoy en día sería completamente obsoleto y trasnochado, sino que era un modo radicalmente errado de leer los textos fundantes y portantes de la fe eclesial. Evidentemente, con estas premisas de partida no solamente era necesario rehacer el método exegético, soslayando completamente la exégesis patrística, sino que, simultáneamente, se minaba completamente la credibilidad del resultado principal obtenido por dicha exégesis: el dogma cristológico y trinitario ${ }^{11}$.

Un examen cuidadoso demuestra carencias notables, desde el punto de vista teológico y metodológico, en el método exegético científico, incluida su falta de fidelidad a puntos esenciales del Concilio Vaticano II con respecto a la hermenéutica que ha de acompañar la labor exegética ${ }^{12}$. Se trata de uno de los debates más álgidos e interesantes de los últimos años en el campo católico, aun sin un resultado definitivo, a pesar de la exhortación postsinodal de Benedicto XVI Verbum Domini, $\$ \$ 29-49$.

6. Como colofón, resulta que la opinión pública otorga credibilidad a la investigación histórica sobre Jesús y sus resultados. Muchos divulgan estos resultados en la catequesis, en la predicación y por otros canales, con el resultado de la propagación más bien de una jesuología, que de la

11 Sobre esta cuestión, entre otros, los siguientes escritos de J. RatZinger, Das Problem der Dogmengeschichte in der Sicht der katholischen Theologie (Wertdeutscher, Köln - Opladen 1966; he consultado la versión italiana: "Il problema della storia dei dogmi nella prospectiva della teologia cattolica“, en Testimonianze 13, Nr. 126 (1970) 510-534); „Christozentrik in der Verkündigung“, en Trierer Theologische Zeitschrift 70 (1961) 1-14, recogido en J. Ratzinger, Dogma und Verkündigung (Wewel, Donauwörth ${ }^{4} 2005$; original 1973), 43-64; ahora en: JRGS 6/2, 647667; Zum Personverständnis der Dogmatik (1966), recogido en Dogma und Verkündigung, 205-223; „Die Christologie im Spannungsfeld von altchristlicher Exegese und moderner Bibelauslegung", en J. Tenzier (ed.), Urbild und Abglanz. Festgabe für Herbert Doms zum 80. Geburtstag (Regensburg 1972) 359-367; ahora en JRGS 6/2, 820-831; „Die Legitimitaet des christologischen Dogmas“, en Estudios Eclesiásticos 47 (1972) 487-503; ahora en JRGS 6/2, 832-849. JRGS = Joseph Ratzinger Gesammelte Schriften, Herder, Freiburg. El volumen 6/2 apareció en 2013.

12 Remito a G. URíbarri, "Exégesis científica y teología dogmática. Materiales para un diálogo", en Estudios Bíblicos 64 (2006) 547-578; G. URíbARri, "Para una nueva racionalidad de la exégesis. Diagnóstico y propuesta”, en Estudios Bíblicos 65 (2007) 253-306; G. URíbarRI, "Exégesis y teología según el Sínodo sobre la Palabra de Dios", en Estudios Eclesiásticos 84 (2009) 41-93. 
fe eclesial ${ }^{13}$. En la celebración litúrgica dominical no pocas veces se puede uno preguntar si el personaje protagonista de la escena evangélica comentada en la homilía se puede identificar con aquel que aparece como segunda persona de la Trinidad en la recitación subsiguiente del credo.

Sin embargo, como hemos visto, la misma investigación histórica, no solamente como programa teológico, sino como empresa científica, está lastrada por prejuicios y problemas de hondo calado. Desde el punto de vista teológico, no solamente desconfía radicalmente del mensajero, la Iglesia, cuyo mensaje estudia, los documentos cristianos primitivos. Además, los lee anti-kerigmáticamente, mientras que las narraciones evangélicas son textos compuestos con una historia kerigmatizada: para transmitir la fe. Esta historia, la de Jesús, se halla impregnada, no inventada, por la Pascua y la fe pascual en la misma composición de los evangelios. Por lo tanto, la operación de la investigación histórica pretende ser capaz de obtener un precipitado del supuesto material bruto original, incontaminado de la fe, a partir de un material que ya se recogió por el impacto significativo que el mismo Jesús causaba y que desde siempre se ha narrado desde esa perspectiva ${ }^{14}$, releído a la luz de la Pascua. Los resultados de esta labor no podrán servir para proponer la fe. Solamente para mostrar que algunos núcleos sustantivos de la misma fe no son una mera invención, sin fundamento alguno: resisten con solvencia el cedazo y la criba de la crítica histórica. Así pues, desde el punto de vista de la propuesta eclesial de la fe, no podemos quedarnos solo con la construcción historicista de Jesús.

b) Una estrategia pastoral contracultural

Un primer error consistiría en despreciar e ignorar la problemática previamente esbozada, de gran calado teórico y de amplia influencia pastoral. Ante este reto, apunto alguna estrategia pastoral.

13 Así W. Kasper, „Bausteine“, 16.

14 La Geschichte en contraposición a la Historie. De un modo más elaborado, cf. J.D.G. Dunn, Jesus Remembered (Christianity in the Making I; Eerdmans, Grand Rapids [Mi] - Cambridge [U.K.] 2003; trad. Jesús recordado [Verbo Divino, Estella 2009]); J.D.G. Dunn, Redescubrir a Jesús de Nazaret. Lo que la investigación sobre el Jesús histórico ha olvidado (Sígueme, Salamanca 2006); O.-Th. Venard, "El testimonio apostólico sobre Jesús y la historia”, en J. J. Fernández SANGrador J. A. Mayoral López (eds.), La Sagrada Escritura en la Iglesia. Actas del Congreso con motivo de la publicación de la Sagrada Biblia, versión de la CEE (BAC, Madrid 2015) 241-266. 
1. Tendiendo puentes, me parece que el interés por Jesús que denota el consumo de literatura sobre el Jesús histórico ofrece también una buena oportunidad para comenzar un diálogo acerca de Jesucristo e ir profundizando en su persona. El gran tesoro de la Iglesia es, sin duda, Jesucristo. Por eso, aunque la aproximación historicista sea insuficiente, se puede considerar un primer paso. A partir de aquí se pueden ir estableciendo las preguntas pertinentes en línea con la génesis de la cristología: desde el Jesús de Nazaret que predica la irrupción del reino de Dios; siguiendo por el porqué de esta transmisión de una tradición acerca de Jesús, su mensaje y el significado de su persona; la superación que se da en Jesús de los moldes judíos de comprensión, hasta la pregunta religiosa que la misma figura histórica de Jesús representa: ¿quién es este que: se pone por encima de la Ley de Moisés, cura enfermedades, expulsa demonios, perdona pecados, llama a un seguimiento radical, ora a Dios invocándolo como Padre-Abbá, come con pecadores, se enfrenta a las autoridades judías y religiosas de su época, muere en cruz y dicen que ha resucitado? Si bien algunas presentaciones historicistas de Jesús dejan mucho que desear desde el punto de vista de su congruencia con la fe eclesial, sin entrar ahora en la problemática metodológica más técnica, no se puede negar que también contamos con buenas presentaciones desde el punto de vista histórico, que pueden constituir un buen comienzo de un diálogo y una conversación seria acerca de Jesucristo ${ }^{15}$.

2. El empleo por los creyentes de un lenguaje claramente confesante. Ha habido épocas en que el mero nombre de Jesús era una expresión confesante. En el mismo NT aparece con ese tenor (cf. p.ej.: Mt 1,21; Hch 4,12; Filp 2,10). Toda una tradición habla con devoción del "dulce nombre de Jesús". Incluso hay una fiesta litúrgica expresamente dedicada a "la imposición del nombre de Jesús" (3 de enero). Sin embargo, en nuestro contexto se ha convertido en el nombre de un personaje histó-

15 Entre las que conozco, y con diferente extensión y complejidad, haciendo una selección recomendaría: J. GNILKA, Jesús de Nazaret, mensaje e historia (Herder, Barcelona 21995); A. Puig, Jesús. Una biografía (Destino, Barcelona 2005); J. Schlosser, Jesús, el profeta de Galilea (Sígueme, Salamanca 2005); G. Theissen - A. Merz, El Jesús histórico. Manual (Sígueme, Salamanca 1999); J.P. MEIER, Un judio marginal. Nueva visión del Jesús histórico. Hasta ahora 5 vols (Verbo Divino, Estella: I. Las raíces del problema y la persona, 32000 ; II/1. Juan y Jesús. El reino de Dios, 2 2000; II/2. Los milagros, 2000; III. Compañeros y competidores, 2003; IV. Ley y amor, 2010; V. Probing the Authenticity of the Parables [Yale U.P., Cumberland (Ri) 2106]). 
rico. No denota espontáneamente una adhesión creyente ni identifica a los creyentes. El manejo que hace del término Jesús la ciencia histórica lo ha alojado en un terreno científicamente neutral y aséptico. Por eso, el primer paso, de gran calado por la capacidad del lenguaje de transmitir toda una cosmovisión, consiste en emplear un lenguaje confesante, también en las circunstancias más ordinarias, fuera del ámbito litúrgico. Sin este paso, nuestro testimonio como Iglesia se desdibuja y descafeína.

3. Dentro de los contenidos de la fe, la resurrección de Jesús adquiere un puesto central. Ninguna catequesis de orden cristológico la debería dejar de lado. Dado que no siempre se cumplen todas las programaciones, en mi opinión sería conveniente que la resurrección fuera uno de los primeros temas y no de los últimos, como suele suceder. Por una parte, la resurrección, en cuanto tal, no forma parte de aquello que resulta accesible a la investigación histórica sobre Jesús, pues con la resurrección Jesús ingresa en otro orden de realidad. No hubo ningún testigo directo de la resurrección. La resurrección nos remite expresamente al ámbito de la fe. Además, con la resurrección se acredita firmemente a Jesús y se descubre en toda su patencia la identidad última y verdadera del personaje histórico (cf. p.ej.: Rm 1,3-4; Filp 2,6-11): es el Hijo de Dios, que está sentado a la derecha del Padre, el Señor del universo.

4. Siguiendo en esta línea, la catequesis cristológica no debería dejar de lado tampoco algunas de las composiciones más densas y, en parte, más antiguas de la primitiva Iglesia: los himnos cristológicos $^{16}$. La mera consideración de los himnos implica ponerse ante el significado protológico, soteriológico y escatológico de la pascua. Así, ante la grandeza de los himnos y su vuelo teológico, el horizonte minimalista de la aproximación historicista se desvela como excesivamente recortado.

5. Por último, la credibilidad de la fe eclesial en Jesús como el Cristo pende, en gran medida, de la credibilidad de la misma Iglesia, sus repre-

16 Cf. p.ej.: M. Hengel, "Hymns and Christology" (1980), recogido en M. Hengel, Between Jesus and Paul. Studies in the Earliest History of Christianity (Fortress Press, Philadelphia 1983) 78-96 + 188-190 y en M. Hengel, Studien zur Christologie. Kleine Schriften IV. (Wissenschaftliche Untersuchungen zum Neuen Testament 201; hg. v. Cl.-J. Thornton, Mohr Siebeck, Tübingen 2006) 185-204; M. Hengel, „Das Christuslied im frühesten Gottesdienst“ (1987), recogido en M. Hengel, Studien zur Christologie, 205-258; F. Ramírez Fueyo, "El himno”, en Sal Terrae 101 (febrero 2013) 167-182. 
sentantes más públicos y sus miembros. La Iglesia es madre y maestra de fe, también de la fe cristológica. Toda mengua en el crédito eclesial dificulta la transmisión de la fe cristológica, en beneficio indirecto de las construcciones historicistas, que se revisten con el halo de la credibilidad científica, o de la increencia o la adscripción a otras confesiones religiosas.

\section{JESUCRISTO: ¿¿UN LÍDER RELIGIOSO ENTRE TANTOS?}

\section{a) Del pluralismo al Relativismo}

1. El pluralismo es una de las señas de identidad de nuestra cultura ${ }^{17}$. Ahora bien, la conclusión espontánea que mayoritariamente se extrae del pluralismo actual es el relativismo. La convivencia pacífica entre cosmovisiones y religiones diferentes exige el respeto y la tolerancia. El paso en falso que se ha dado masivamente ha sido concluir que el respeto y la tolerancia a todas las cosmovisiones implica la renuncia a la existencia de la Verdad: una verdad única. Más todavía, conduce a la convicción de que incluso en el caso de que esa Verdad única, sobre Dios, el mundo, el hombre, existiera, no podría ser patrimonio exclusivo de ninguna visión, cosmovisión o religión. Sino que o nadie la alcanzaría, al menos en su plenitud íntegra, o todos la poseerían por igual o no existiría medio humano para poder erigirse sensatamente en detentadores de la plenitud de la Verdad ${ }^{18}$. Quien así se presente en la cultura pluralista será tachado de fundamentalista: enemigo de la convivencia pacífica, alejado de los eximios e imprescindibles valores cívicos de la tolerancia y el respeto.

2. Como conclusión de las premisas anteriores, en nuestra actual cultura plural todas las religiones se perciben y entienden como caminos igualmente válidos, o inválidos, hacia Dios o el Absoluto, o para mejorar la vida humana aquí ahora: afrontar la muerte, la enfermedad, la vida fa-

17 Cf. p. ej.: Ch. TAYlor, A Secular Age; P.L. Berger, Los numerosos altares de la modernidad. En busca de un paradigma para la religión en la época pluralista (Sígueme, Salamanca 2016; original 2014).

18 La reivindicación de la existencia de la Verdad y la posibilidad de conocerla ha sido una constante en las preocupaciones teológicas y culturales de J. Ratzinger Benedicto XVI. Se puede sospechar su mano en la encíclica de JuAn PABlo II, Fides et ratio, alineada en esta posición. Cf. p.ej. J. RATZINGER, $F$, verdad y tolerancia. El cristianismo y las religiones del mundo (Sígueme, Salamanca ${ }^{5} 2005$ ). 
miliar, el trabajo, la convivencia política, las decisiones morales, etc. La llamada teología pluralista de las religiones se sitúa aquí de pleno, dando forma y personalidad teológica a esta tendencia cultural de fondo ${ }^{19}$.

No han faltado las manifestaciones del magisterio en contra de esta postura teológica, reafirmando la unicidad y singularidad de Jesucristo, como el mediador absoluto, pleno y único de la salvación y la revelación. La más nítida y destacada, sin duda, fue la Declaración Dominus Iesus, por parte de la Congregación para la Doctrina de la Fe en el año $2000^{20}$. Pocos años antes, 1996, la Comisión Teológica Internacional publicó un buen documento sobre esta temática ${ }^{21}$. Sin embargo, la teología pluralista de las religiones conserva la vigencia social y sigue produciendo un impacto notable en los ambientes eclesiales. Así se desprende de la intervención del secretario de la Congregación para la Doctrina de la Fe, Mons. Luis F. Ladaria, SJ, en el encuentro de las comisiones doctrinales de las conferencias episcopales europeas tenido en enero de 2015. Se le encargó una ponencia sobre: La unicidad de Cristo y de la Iglesia. Para justificar su intervención, Ladaria advierte que si bien el tema es bien conocido, la cuestión "se repropone a menudo" en muchos países de

19 Sobre el particular: A) Para una primera información: M. FÉDOU, Las religiones según la fe cristiana (Desclée, Bilbao 2000). B) Para una confrontación crítica, entre muchos: L. F. LADARIA, Jesucristo, salvación de todos (San Pablo, Madrid 2007); L. F. LADARIA, "El cristianismo y la universalidad de la salvación”, en Estudios Eclesiásticos 81 (2006) 353-381; L. F. LADARIA, "La encarnación de Dios y la teología cristiana de las religiones", en A. Cordovilla Pérez y otros (dirs.), Dios y el hombre en Cristo. Homenaje a Olegario González de Cardedal (Sígueme, Salamanca 2006) 223243; L. F. Ladaria, "Cristo, la Iglesia, las religiones", en V. Vide - J.R. Villar (eds.), El Concilio Vaticano II. Una perspectiva teológica (San Pablo, Madrid 2013) 399-435. Por mi parte, me he pronunciado sobre el tema en: G. URíbarRI, La singular humanidad, 205-337; G. URíBARRI, "Multiculturalidad. Una perspectiva teológica", en Razón y Fe 253 (febrero 2006) 131-142; G. URíbarri, "Desafíos teológicos del pluralismo religioso", en Communio Nueva Época 12 (primavera 2009) 59-71; G. URíBARRI, “Jesucristo, mediador y plenitud de toda la revelación”, en A. Del Agua Pérez (ed.), La constitución dogmática Dei Verbum a los cincuenta años de su promulgación (BAC, Madrid, en prensa).

20 Hay una edición con comentarios: Congregación para la Doctrina de la Fe, Declaración "Dominus Iesus". Documentos, comentarios y estudios (Palabra, Madrid 2002).

21 Comisión Teológica Internacional, "El cristianismo y las religiones" (1996), en Comisión Teológica Internacional, Documentos 1969-1996, ed. por C. Pozo (BAC, Madrid 1998) 557-604. 
todos los continentes, si bien de modo más agudo fuera de Europa ${ }^{22}$. El último documento oficial de la Conferencia Episcopal española, Jesucristo, salvador del hombre y esperanza del mundo (abril 2016), también se hace eco, suficientemente amplio, de esta preocupación ${ }^{23}$.

3. Dado que he tratado por extenso este tema recientemente ${ }^{24}$, me ceñiré a lo más sustantivo del mismo, resumiéndolo en una afirmación y dos puntos.

La afirmación sostiene que pensar en Jesucristo como un líder religioso más, uno entre otros, sin otorgarle la plenitud absoluta de la salvación y la revelación, implica deshacer la misma fe cristiana, porque disuelve su mismo centro. Por ello, la postura de la Iglesia en este punto no tiene que ver ni con complejo de superioridad ni con eurocentrismo ni con altanería ni con el desprecio a otras religiones y sus miembros ni con un atentado a la convivencia democrática. Al contrario, pocas instituciones como la Iglesia católica, desde la declaración Dignitatis humanae del concilio Vaticano, se han empeñado en la defensa de la libertad religiosa para todos, evidentemente también para los cristianos. Se trata, llana y simplemente, de mantener y sostener el núcleo mismo del cristianismo. Esto se percibe en los dos puntos siguientes.

Primero y sin prejuzgar lo que otras religiones estimen de sus propios líderes religiosos o fundadores, ya sea Buda, Mahoma u otros, le pertenece a la esencia del cristianismo el hecho de que el sujeto revelador, Jesucristo, coincide totalmente con el objeto revelado, Jesucristo. El primer capítulo de la Dei Verbum, sobre la naturaleza de la revelación, de ipsa revelatione, gira sobre este punto (cf. esp. DV 2 y 4 ) ${ }^{25}$. Por lo tanto, si Jesucristo pasa a ser uno más entre otros líderes religiosos de estatura semejante, entonces ni es el revelador de Dios ni es el contenido de la revelación, a la que la fe cristiana asiente (DV 5). Sin embargo, el núcleo

22 Cf. L. F. Ladaria, Unicità di Cristo e della Chiesa (Esztergom, 13 de enero de 2015). Accesible en: http://www.vatican.va/roman_curia/congregations/cfaith/incontri/rc_ con_cfaith_20150113_esztergom-ladaria_it.html (Consulta 24.08.2016).

23 Conferencia Episcopal Española, Jesucristo, salvador del hombre y esperanza del mundo. Instrucción pastoral sobre la persona de Cristo y su misión (Edice, Madrid 2016), $\$ \$ 25-33$.

24 Véase la nota 19.

25 Véase el magnífico comentario de H. DE LubAC, "Comentario al preámbulo y al capítulo primero", en B.-D. Dupuy (dir.), La revelación divina. Constitución dogmática "Dei Verbum" I (Taurus, Madrid 1970) 181-367, esp. 211-212. 
del credo afirma que Jesucristo es el Hijo de Dios, encarnado por nosotros y por nuestra salvación, que nos ha revelado el rostro del Padre, que nos ha concedido el perdón de los pecados por su muerte sacrificial y redentora en la cruz, que por el don de su Espíritu nos hace hijos de Dios.

Segundo, la consideración de Jesús como un líder religioso más niega de modo directo la encarnación, pues si Jesús es verdaderamente Dios, Hijo de Dios, la segunda persona de la Trinidad, no se puede rebajar un ápice su carácter de mediador y plenitud de la revelación. En Jesucristo Dios mismo, en persona, nos habla y comunica el rostro de Dios ${ }^{26}$. Ahora bien, la encarnación ostenta un asiento sólido en el NT. Al texto capital del prólogo de Juan (Jn 1,1-18), se le han de sumar, al menos, en combinación dinámica e interactiva con el mismo prólogo:

a) los textos de envío en Pablo (ej. Gal 4,4-5; Rm 8,3) y, sobre todo, del evangelio de Juan (con el verbo pémpein: Jn 5,37; 6,44; 8,16.18; 12,49; 14,24.26; cf. 5,23; el Padre envía: Jn 4,34; 5,24.30; 6,38.39; $7,16.28 .33 ; 8,26,29 ; 9,4 ; 12,44.45 ; 13,20 ; 15,21 ; 16,5$; y con el verbo apostéllein, bien con Dios como sujeto: Jn 3,17.34; 8,42; cf. 6,29; o con el Padre: Jn 5,36; 6,57; 10,36; 20,21; 5,38; 6,29; 7,29; 11,42; 17,3.8.18.21.23.25);

b) las afirmaciones relativas a la preexistencia (ej. Filp 2,5-6);

c) las de la mediación en la creación (ej. Col 1,15-20; Heb 1,2-3; 1Cor $8,6) \mathrm{y}$

d) las afirmaciones relativas al nacimiento virginal (cf. Mt 1,18.20.23; Lc 1,35; Jn 1,13 sería más dudoso).

Además, en su discernimiento del cogollo central de la fe, la Iglesia ha considerado la encarnación, todas sus consecuencias incluidas, como perteneciente a su núcleo más sustantivo.

\section{b) HACER VALER LA ENCARNACIÓN Y SU FUNDAMENTO}

A pesar de sus dificultades, el hecho de que en el discurso sobre la religión y lo religioso se barajen distintas religiones también supone una oportunidad para mostrar "lo diferencial cristiano" (R. Guardini) en este campo. Así, me parece que se crea también un ambiente oportuno

26 "El rostro de Dios es el Logos, por medio del cual Dios se hace visible y es conocido" (Clemente Alejandrino, Pedagogo, I,57,2; Fuentes Patrísticas 5,192). 
para hacer ver lo que significa para los cristianos: la misericordia divina y la gracia; el ser personal de Dios y, derivadamente, de los humanos; la alteridad filial en la relación con Dios. Todos estos elementos están ausentes en las grandes tradiciones orientales y desde luego no figuran tal cual en el islam ${ }^{27}$.

Con las últimas indicaciones del epígrafe anterior ya se han ofrecido unas pistas pastorales suficientemente claras. En este ámbito, con frecuencia los partidarios de la teología pluralista apelan a ciertos resultados de la investigación histórica sobre Jesús. Ambos rebajan el significado de Jesucristo. Por eso, estimo conveniente hacer valer todos los textos que apuntan hacia la encarnación. Ya sean los anteriormente mencionados, como aquellos que nos hablan de Jesucristo como aquel en quien habita corporalmente la plenitud de la divinidad (cf. p.ej. Col 1,19; 2,9) o que lo cualifican como el mediador absoluto (p.ej. 1Tim 2,4-6), el camino verdadero hacia Dios (Jn 14,6). Estos testimonios vinculantes de la primitiva fe ni se pueden ignorar ni se deben interpretar a la baja.

\section{JESUCRISTO: ¿UN GUÍA PARA MI BIENESTAR ESPIRITUAL?}

a) Jesucristo en el mercado de la espiritualidad y la mística

1. En nuestra sociedad plural la religión se ha convertido en espiritualidad $^{28}$. Concomitantemente o, más bien, como causa de lo anterior, la búsqueda religiosa se ha transformado en una búsqueda espiritual

27 Una primera introducción en $\mathrm{CH}$. Troll, Dialogar desde la diferencia. Cómo orientarse en las relaciones entre cristianos y musulmanes (Sal Terrae, Santander 2010).

28 Ch. Taylor, A Secular Age, esp. 505-535. Congregación para la Doctrina de LA FE, "Carta sobre algunos aspectos de la meditación cristiana" en AAS 82 (1990) 362-379; recogido en Congregación para la Doctrina de la FE, Documenta. Documentos publicados desde el Concilio Vaticano II hasta nuestros días (Palabra, Madrid 2007) No 70, p. 320-332. Consejo Pontificio de la Cultura - Consejo Pontificio para el Diálogo Interreligioso, Jesucristo, portador del agua de la vida. Una reflexión sobre la "Nueva Era" (febrero 2003. Página web del vaticano. Consulta 20.7.2015). Véase también: Congregación PARA la Doctrina de la Fe, La meditación cristiana. Carta "Orationis formas" (Palabra, Madrid 1994); Mons. L.F. Ladaria, "Sobre «Orationis formas». Carta a los Obispos de la Iglesia Católica sobre algunos aspectos de la meditación cristiana (15 de octubre de 1989)", en I. Catela Marcos (ed.), La oración, fuerza que cambia el mundo (BAC, Madrid 2016) 3-24; G. URíbArRI, “Tres cristianismos insuficientes: emocional, ético y de 
personal (personal journey), marcada por el sincretismo. Ciertamente, aunque este aspecto no disuena de la consideración de Jesucristo como un líder religioso más y se alimenta de esa percepción en muchas personas, en mi opinión posee un perfil suficientemente diferenciado como reto particular para la fe cristiana, para su misma comprensión, transmisión, irradiación y configuración de la existencia de los propios cristianos creyentes, nada inmunes a este modo de creer $^{29}$. Mientras que la percepción de Jesucristo como un líder religioso más conoce una fundamentación teórica más elaborada que la propone, incluso dentro del panorama teológico, como es la teología pluralista de las religiones, este aspecto no goza de tanta elaboración intelectual o, al menos, se encuentra mucho más dispersa. Además, se orienta con fuerza hacia la vivencia emocional y espiritual de la fe, en el marco del magma de la oferta sincrética, psicologizante, pseudomística, terapéutica y espiritualizante tan en boga hoy en día.

2. Esta corriente también disuelve y desnaturaliza la concepción cristiana de Jesucristo ${ }^{30}$. Se pretende ofrecer una versión aquilatada de la espiritualidad cristiana para nuestros tiempos, pero el mensaje de Jesús y su misma persona se leen desde claves muy ajenas, como por ejemplo: convertirlo en mero maestro interior ${ }^{31}$, la eliminación del pecado, el silencio apofático ante Dios, la eliminación de la alteridad con Dios, la combinación de la resurrección con la reencarnación y una soteriología de carácter cósmico ${ }^{32}$.

autorrealización. Una reflexión sobre la actual inculturación del cristianismo en Occidente", en Estudios Eclesiásticos 78 (2003) 301-331, 307-315.

29 W. KASPER, „Bausteine“, 21, incluye este aspecto dentro de la problemática general de la relación del cristianismo con las religiones. Lo describe así: „Im modischen Trend liegen schließlich eine spätmoderne agnostische, oft synkretistische Spiritualität und Esoterik wie eine pantheistische Weltfrömmigkeit ohne persönlichen Gott, ohne Christus und ohne Kirche". ("Finalmente, en la tendencia de moda se da una espiritualidad y un esoterismo de la modernidad tardía, agnóstico, con frecuencia sincrético, así como una devoción cósmica de carácter panteísta sin Dios personal, sin Cristo y sin Iglesia”. Trad. propia libre).

30 Remito a G. URíbarri, La mística de Jesús. Desafío y propuesta (Sal Terrae, Santander 2017); O. González de Cardedal, Cristianismo y mistica (Trotta, Madrid 2015).

31 Tendencia de J. Melloni, El Cristo interior (Herder, Barcelona 2010; con reediciones).

32 Muchos de estos elementos están presentes, por ejemplo, en A. Nolan, Jesús hoy. Una espiritualidad de la libertad radical (Sal Terrae, Santander 2007); J. MeLLONI - 
b) Recuperar la oferta espiritual cristiana

Desde luego la sed de espiritualidad, con lo que denota de sed de Dios, no puede menos que ser bienvenida. Además, hemos citado con aprobación en innumerables ocasiones la sentencia de Rahner:

"[... ] cabría decir que el cristiano del futuro será un «místico», es decir, una persona que ha experimentado algo, o no será cristiano. Porque la espiritualidad del futuro no se apoyará ya en una convicción unánime, evidente y pública, ni en un ambiente religioso generalizado, previos a la experiencia y a la decisión personales" ${ }^{33}$.

Por consiguiente, esta demanda no nos debería pillar desprevenidos. Lo lógico, de compartir el análisis del gran teólogo de Friburgo, sería que en las comunidades cristianas este elemento se hubiera cuidado con mimo y, además, que los cristianos de a pie nos hubiéramos convertido en guías capaces de iniciar a otros en los caminos de la espiritualidad, la oración y la mística cristiana. Así, pues, bienvenida sea la era de la espiritualidad.

En este contexto, hemos de realizar una doble operación con urgencia. En primer lugar, ofrecer en toda su gama, variedad y profundidad la espiritualidad propiamente cristiana: en parroquias, santuarios, oratorios, colegios católicos, casas de espiritualidad, monasterios, editoriales, movimientos y grupos cristianos, retiros, cofradías y hermandades, etc. Como la oferta espiritualizante y mistizante recién descrita obtiene con relativa facilidad un éxito inicial grande y genera sensación muy inmediata de bienestar en sus consumidores, corremos el serio peligro de que sea el mercado del consumo religioso-espiritual quien oriente nuestras decisiones y ofertas, dejando de lado o en suspenso la lógica inherente a nuestra fe. Mal servicio estaríamos haciendo a la fe cristiana y a su propagación si nos dejamos llevar por la demanda: no pide cristianismo, sino esoterismo sincrético psicologizante terapéutico y emocional. Elementos de este nuevo gnosticismo ya se han introducido en algunos ambientes, con todas las bendiciones a veces, e imponen su lógica implacable.

J. Сово, Dios sin Dios (Fragmenta, Barcelona 2015; siempre por parte de Melloni); W. JäGER, La ola es el mar. Espiritualidad mística (Desclée, Bilbao 2013).

33 K. Rahner, "Espiritualidad antigua y actual", en K. Rahner, Escritos de Teología VII (Taurus, Madrid 1969; original 1966), 13-35, 25. Repite la misma idea en K. Rahner, „Elemente der Spiritualität in der Kirche der Zukunft“, en K. RaHner, Schriften zur Theologie XIV. (Benziger, Zürich - Einsiedeln - Köln 1980) 368-381, 375-376. 
En segundo lugar, hemos de mostrar la coherencia, la profundidad y el atractivo propio de la espiritualidad cristiana, de la espiritualidad y la mística de Jesús. Yendo a su núcleo último, estimo que se da una confrontación de fondo entre tres alternativas fundamentales en el terreno de la espiritualidad que hoy están en pugna como las tres grandes ofertas presentes en el mercado religioso de nuestro entorno, si ahora hacemos abstracción del budismo y el islam en su estado puro. (a) Una salvación y una espiritualidad últimamente centrada en el propio sujeto: su capacidad de meditación, relajación, ascesis y concentración, sin el auxilio divino. Este elemento le pertenece al misticismo oriental y a su decantación, ciertamente light, en las sociedades occidentales postmodernas. (b) Una salvación y una espiritualidad cósmica, que confía últimamente en el universo, sus procesos y su energía, como aquella madre cósmica que finalmente nos acogerá tiernamente en su seno. Aquí no queda nada claro cómo se mantiene el ser personal de cada individuo. La denominada "Nueva Era", con todo su sincretismo, está propugnando esta alternativa. (c) El ejercicio filial de la libertad, sostenido por la gracia de Dios. He aquí la propuesta cristiana de espiritualidad.

Por eso, hemos de mostrar la idiosincrasia espiritual de Jesús, como maestro, sin tergiversaciones: su ser filial como la clave de su persona y la fuente de su espiritualidad y mística; la inhabitación del Espíritu como lo que le conduce y pone en contacto íntimo con el Padre y su voluntad; su modo propio de orar (ej.: padrenuestro), que transmitió a los discípulos; su capacidad para afrontar el conflicto e incluso la muerte, por obediencia a la voluntad de Dios; su gloriosa resurrección, que muestra su identidad y rubrica la verdad de su camino. De todo ello se sigue una comprensión excelsa de nuestra libertad creatural, invitada a proseguir el camino de Jesús como vía regia que conduce al Padre mediante el Espíritu. Así refulge la dignidad de la libertad creatural, el peso ineluctable y siempre dramático de nuestra responsabilidad personal, sostenido por la gracia y la misericordia de Dios, que nunca falta.

\section{JesUCRISTO: ¿'Mi SALVADOR?}

a) Una sociedad ansiosa de salvación en una cultura necesitada de salvación

1. La modernidad tardía y líquida genera estrés y angustia de modo estructural y sistémico ${ }^{34}$. Por eso, nada extraño que la búsqueda religiosa

34 Z. Bauman, Modernidad líquida, esp. 11-13. 
se articule con un fuerte componente soteriológico, que suele más bien revestir una tonalidad terapéutica. La necesidad de terapia, curación, sanación, bienestar impera hoy en nuestra sociedad y cultura, ya sea bajo ropajes religiosos, pseudo-religiosos o a-religiosos. Sin embargo, en su fondo se puede entender y leer como una búsqueda de salvación.

El hombre postmoderno medio busca afanosamente salvación intramundana: para el aquí y el ahora ${ }^{35}$. Por eso, mucha de la salvación que se busca y a la que el mercado responde con una oferta muy variada, de tal modo que cada uno la puede personalizar, tiene que ver con el cuerpo: dietas, tratamientos de belleza, cuidado de la nutrición sana y ecológica, ejercicios de yoga o pilates, deporte en todas sus variedades, etc. Baste con atender a la difusión de los centros de wellness y fitness. Como gran diagnosticador, nos dice Z. Bauman:

"El cuerpo, podríamos decir, se ha convertido en santuario y último refugio de la continuidad y la duración; sea lo que fuere que signifique «largo plazo", no puede exceder los límites establecidos por la mortalidad corporal. El cuerpo se está convirtiendo también en la última línea de trincheras de la seguridad, expuesta al constante bombardeo del enemigo, o en el último oasis entre las arenas agitadas por el viento. De allí la rabiosa, obsesiva y febril preocupación por defender el cuerpo" 36 .

2. El anuncio de Jesús y su misma vida se pueden resumir acertadamente con la palabra evangelio: buena noticia. El evangelio de Jesucristo es una buena noticia de salvación. Muchos de sus contemporáneos así lo vivieron, especialmente quienes percibieron de modo más palmario los beneficios del encuentro con el Salvador, aquellos a quienes Jesús curó de alguna dolencia o enfermedad, como signo de la irrupción de la gracia de Dios, del Dios de la Vida (curaciones); aquellos de los que Jesús expulsó un demonio o varios, como señal de la irrupción de la familiaridad y el poder de Dios, frente al Adversario que perjudica con dolor y sufrimiento a los humanos (exorcismos); aquellos a quienes Jesús perdonó sus pecados, los restableció como miembros de pleno derecho del pueblo santo y los reconcilió con Dios (perdón de los pecados); aquellos a quienes Jesús se acercó para trasmitirles directamente la buena noticia

35 Todavía resulta interesante R. DíAz-SALAZAR y otros (eds.), Formas modernas de religión (Alianza, Madrid ${ }^{2}$ 1996; original 1994).

36 Modernidad líquida, 194. 
del reinado de Dios y del Dios del reino, como el que es misericordioso y acoge a todos, incluso a los pecadores más clamorosos (comidas con publicanos y pecadores ${ }^{37}$. Sobre esta base sólida, la comunidad cristiana entendió que toda la persona, toda la vida y todo el ministerio de Jesús, su encarnación, enseñanza, actuaciones, muerte ignominiosa en la cruz y posterior resurrección gloriosa, obraban la salvación de Dios.

Sin embargo, hoy en día nos topamos con una enorme dificultad para presentar y propagar la salvación cristiana en nuestra sociedad y cultura. Mientras que Jesús, en su época, proponía y hacía presente una salvación que no todos acogieron, pero muchos comprendieron, nuestro lenguaje de salvación se encuentra en serias dificultades ${ }^{38}$. Nos encontramos en una situación, en la que no se alcanza a cumplir el criterio que A. Tornos formula para una inculturación lograda de la fe: "El criterio para el servicio a la fe en la cultura últimamente tendría que ser este: que se entiendan las palabras de la fe, que se entiendan las obras de la fe, que den casi envidia las celebraciones de la fe" ${ }^{39}$.

No puede menos que constituir una pregunta de recio alcance el auge de los pentecostales, en todas sus modalidades. Según Berger, en unos lustros han alcanzado los 600 millones de fieles ${ }^{40}$. En su lado opuesto, resulta complejo hacer ver el carácter salvífico de la muerte en cruz de Jesús desde las categorías de sacrificio expiatorio y representación vicaria $^{41}$.

37 Una presentación entre muchas: Y. Congar, Un pueblo mesiánico. La Iglesia, sacramento de la salvación. Salvación y liberación (Cristiandad, Madrid 1976) 123-176.

38 Cf. el análisis y la propuesta de B. SesBoüÉ, Jesucristo, el único mediador. Ensayo sobre la redención y la salvación 2 vols. (Secretariado Trinitario, Salamanca) 1990 y 1993. Como complemento, cf. J. Werbick, Soteriología (Herder, Barcelona 1992); F. García Martínez, La humanidad re-encontrada en Cristo. Propuesta de soteriología cristiana a la luz de la antropología de René Girard (U.P. Salamanca, Salamanca 2006).

39 A. Tornos, El Servicio a la Fe en la Cultura de Hoy (Paulinas, Madrid 1987) 35. Véase, más elaborado: A. Tornos, Inculturación. Teología y método (U.P. Comillas - Desclée, Madrid - Bilbao 2001).

40 P. BERGER, Los numerosos altares, 56-61 y 120-125.

41 Cf. la constatación de W. KASPER, „Bausteine“, 19. Destacan, entre otros, los loables intentos de H.U. von Balthasar, „Über Stellvertretung“, en H.U. von Balthasar, Pneuma und Institution. Skizzen zur Theologie IV. (Johannes Verlag, Einsideln 1974) 401-409; trad. Ensayos teológicos IV (Encuentro - Cristiandad, Madrid 2008) 331337; M. Hengel, „Der stellvertretende Sühnetod Jesu. Ein Beitrag zur Entstehung 
3. Ciertamente, desde el punto de vista teórico del quehacer teológico, reina un consenso, pacíficamente poseído, acerca de la necesaria impostación soteriológica de la teología, en general, y de la cristología, en particular ${ }^{42}$. Lo que se desea, otra cosa es si se consigue, es presentar la salvación cristiana como un eje o una dimensión transversal de la fe y la teología, y, más intensa y específicamente, de la cristología. Es decir, no bastaría con añadir un apéndice de soteriología a la cristología, como incluyendo un pequeño tratadito soteriológico en la cristología, sino mostrar el carácter salvífico del evangelio de Jesucristo de un modo consistente, de tal manera que habría de permear el tratamiento de los temas. Esto no obsta, para, igual que con otros temas, como la identidad última de Jesucristo, ofrecer una consideración más monográfica sobre la salvación ${ }^{43}$. Desde mi propia lectura personal, la obra teológica de J. Ratzinger, ciertamente su trilogía sobre Jesús, está concebida desde esta impostación soteriológica general. Su tesis central se puede formular así: siendo Jesús el Hijo, nos puede traer a Dios y la salvación de Dios.

\section{b) Anunciadores y testigos de una buena noticia}

Dado que el cristianismo se entiende a sí mismo como una buena noticia de salvación, el hecho de la búsqueda de salvación integral, más allá del consumo, supone un acicate para presentar la comprensión y la oferta cristiana de salvación. Además, por ejemplo, el cristianismo siempre ha defendido el valor, la nobleza y la importancia del cuerpo, tanto en la cristología como en la antropología (frente al docetismo y al gnosticismo), como en la soteriología (resurrección de los cuerpos). Es más, los mismos sacramentos y la liturgia cristiana en cuanto tal implica la asunción en todo su peso de nuestro ser corporal. Las formas de oración y de espiritualidad cristiana tampoco desatienden al cuerpo. Hay toda

des urchrischtlichen Kerygmas“, en Internationale katholische Zeitschrift Communio 9 (1980) 1-25 y 135-47; J. Ratzinger, Obras Completas, VI/1, 559-567 (= Jesús de Nazaret II [Encuentro, Madrid 2011] 267-279).

42 Cf. p.ej.: E.J. Justo Domínguez, "Soteriología alemana contemporánea", en: Estudios Eclesiásticos 89 (2014) 191-207.

43 Cf. p. ej. la diversidad de enfoques de O. González de Cardedal, Cristología (BAC, Madrid 2001) esp. 493-586; D. HerCsik, Il Signore Gesù. Saggio di cristologia e soteriologia (Dehoniane, Bologna 2010) esp. 66-89 y 145-201; J. Rico PAVÉs, Cristología y soteriología (BAC, Madrid 2016) esp. 423-460. 
una tradición de la importancia del ayuno ${ }^{44}$, la respiración, la postura y los movimientos corporales. Siendo todo esto cierto, también lo es que la fe cristiana venera el cuerpo entregado y roto y la sangre derramada de su Señor. Por eso, no puede comulgar con ciertas formas de culto al cuerpo $^{45}$, como un fin en sí mismo.

Simplificando al máximo, me parece que en este ámbito tenemos planteados dos grandes retos interrelacionados: uno que se puede considerar de orden más teórico y otro de tenor más práctico.

1. Para empezar, parece difícil anunciar una salvación que no sabemos explicar ni de la que sabemos hablar de modo inteligible, primero, para nosotros mismos y, posteriormente, para aquellos interesados, curiosos o buscadores. Por ello, se nos impone como labor lograr articular un lenguaje eclesial suficientemente compartido y significativo sobre:

a) La salvación cristiana en su incidencia en el mundo y la sociedad aquí y ahora. La irrupción presente del reino de Dios, anunciada e inaugurada por Jesús, apunta en esta dirección. Más allá de los discursos más o menos acertados sobre el reino, su construcción y su presencia, hemos de ser capaces de expresar y mostrar su significado de modo inteligible. El papa Francisco nos urge a que la Iglesia sea en cierto sentido sacramento de la misericordia de Dios, traduciendo así su propio ser sacramental, afirmado en el Concilio Vaticano II ${ }^{46}$. No cabe duda de que allí donde se implanta la Iglesia, se fundan escuelas y hospitales, abiertos a todos, y se activa la promoción de la mujer.

b) Aunque la sociedad y la cultura sean renuentes a una salvación transcendente, la fe cristiana no puede dejar de lado esta dimensión fundamental de su comprensión de la salvación. Además, todo el esoterismo, reencarnación incluida ${ }^{47}$, se adentra en este espacio, mientras

44 Cf. el excelente artículo P. Deseille, "Jeûne”, en Dictionnaire de Spiritualité VIII (1974) c. 1164-1175.

45 Cf. J. Ratzinger, "Herido por la flecha de la belleza. La cruz y la nueva estética de la fe”, en J. Ratzinger, Caminos hacia Jesucristo (Cristiandad, Madrid 2004) 33-41; ahora en JRGS 6/2, 777-784.

46 Cf. Francisco, Evangelii gaudium, $\$ 112$; Francisco, Bula Misericordiae vultus; Francisco, Carta apostólica Misericordia et misera.

47 G. Uríbarri, "La reencarnación en Occidente", en Razón y Fe 238 (julio-agosto 1998) 29-43; G. URíbARri, "La inculturación occidental de la creencia en la reencarnación”, en Miscelánea Comillas 56 (1998) 297-321. 
que desde la Iglesia en los últimos decenios hemos sido más bien renuentes ${ }^{48}$. Aquí entra todo un campo, sensible y oportuno, que tiene que ver con afrontar la enfermedad grave, la pérdida de los seres queridos y la propia muerte. Estoy persuadido de que se puede realizar una gran labor. Nos falta, entre otras cosas, un imaginario cristiano del más allá para poder hablar de él ${ }^{49}$.

c) A pesar de las dificultades antedichas, tampoco podemos dejar de lado el carácter salvífico de la muerte en cruz por parte de Jesús, el Hijo de Dios, nuestro Salvador y Redentor. Curiosamente, la religiosidad popular posee aquí una mayor capacidad de penetración y de tocar fibras hondas de la persona, que la elucidación más teórica.

2. Por otra parte, si pregonamos que estamos en contacto con un verdadero Salvador, dicha salvación habrá de traslucirse de algún modo en nuestra vida, si es que verdaderamente nuestro supuesto Salvador es capaz de obrar salvación y nosotros de ingresar en lo que me gusta denominar el estatuto de la vida salvada. No podemos eludir el sarcasmo irónico de Nietzsche, con su certera capacidad de diagnosticar: "Para que yo creyese en su Redentor, tendrían que cantar otras canciones, y sus discípulos tendrían que parecer más redimidos" ${ }^{50}$. De un modo más teológico, A. Tornos sentenció: "no se entra en nuevas esperanzas, por mucho que se anuncien, si no se entra en las formas de vida que se corresponden con ellas" ${ }^{\prime 1}$. Lo dicho sobre la esperanza se aplica a la perfección a la salvación.

Como Iglesia, este aspecto nos presenta al menos estos retos:

a) Construir la nueva sociedad como salvados, que desde la salvación recibida se implican en las causas de la justicia, la ecología y la atención a los pobres, indigentes y menesterosos.

48 Ya dijo S. DEL CURA, "Escatología contemporánea: la reencarnación como tema ineludible", en VARIOS, Teología en el tiempo (Burgos 1994) 309-358, nota 37, p. 320, que la escatología era "la niña pobre" de la catequesis posconciliar. Cf. F.-X. Durrwell, El más allá. Miradas cristianas (Sígueme, Salamanca 1997); B. SeSBOÜÉ, La resurrección y la vida (Mensajero, Bilbao 1998).

49 Cf. G. URíbarri, "Necesidad de un imaginario cristiano del más allá”, en Iglesia viva 206 (abril - junio 2001) 45-82.

50 Así habló Zaratustra, en Obras Completas III (Buenos Aires 1961) 293. Citado por A. Torres Queiruga, Recuperar la salvación (Sal Terrae, Santander 1995) nota 5, p. 225.

51 A. Tornos, Escatología II (U.P. Comillas, Madrid 1991) 19. 
b) Manejar en nuestra convivencia ordinaria un lenguaje de salvados, que conecte con nuestra sonrisa de salvados, alejada y diferente a la queja ordinaria por el estrés y la angustia que genera nuestra sociedad.

c) Celebrar nuestra fe como salvados, de tal modo que en la liturgia no solamente irrumpa la mistagogía, sino también la alegría contagiosa de la salvación. Los pentecostales nos llevan la delantera.

d) Vivir, en definitiva, la alegría de sabernos salvados, vivir la alegría del evangelio, a la que nos convoca el papa Francisco, para que brote por todos los poros de nuestro ser, descolocando a quienes se crucen en nuestro camino y generando la pregunta por el tesoro escondido que nos habita. 
